\title{
Ignorância e Intervenção em Hayek e Popper
}

\author{
Ignorance and intervention \\ in Hayek and Popper
}

CELIA LESSA KERSTENETZKY*

RESUMO: No nascimento da economia moderna, há a afirmação de que o mundo social é um efeito não intencional de decisões e ações individuais, um ambiente de conhecimento limitado ou "ignorância". No século XX, dois filósofos se destacaram no que diz respeito ao desenvolvimento dessa ideia - Friedrich Hayek e Karl Popper. No entanto, não se pode afirmar com segurança que Popper e Hayek estavam em sintonia com as implicações da ignorância para a intervenção do governo na atividade econômica. Neste artigo, argumento que, em contraste com o liberal-conservador Hayek, Popper reconhece um importante papel legítimo do governo e da política democrática no aperfeiçoamento da vida social, precisamente por causa do problema do conhecimento limitado.

PALAVRAS-CHAVE: Popper; Hayek; intervenção governamental; democracia; ignorância.

ABSTRACT: In the birth of modern Economics there is the statement that the social world is an unintended effect of individual decisions and actions, an environment of limited knowledge or "ignorance". In the XXth century, two philosophers stood out as far as the development of this idea is concerned - Friedrich Hayek and Karl Pop- per. However, one cannot safely assert that Popper and Hayek were attuned with respect to the implications of ignorance to government intervention on economic activity. In this article, I argue that, in contrast to the liberal-conservative Hayek, Popper acknowledges an important legitimate role for government and democratic polity in perfecting social life, precisely on account of the problem of limited knowledge.

KEYWORDS: Popper; Hayek; government intervention; democracy; ignorance.

JEL Classification: B25; B40.

Uma das proposições mais instigantes das Ciências Sociais, e que deu origem à Economia moderna, é a que afirma ser o mundo social resultado não pretendido de decisões e ações de indivíduos. No século XX, dois autores austríacos se desta-

\footnotetext{
* Professora do Departamento de Economia da Universidade Federal Fluminense - UFF, Niterói-RJ, Brasil e-mail: celiakersten@terra.com.br. Submetido: março 2003; aceito: setembro 2003
} 
caram pelo desenvolvimento dessa proposição a partir dos anos 1930, Friedrich von Hayek e Karl Popper. Enquanto Hayek desdobraria seus meandros organicistas e evolucionistas, seguindo a tradição inaugurada por Carl Menger, e os enfeixando na noção de ordem espontânea ou catalaxia, Popper dedicaria particular atenção à crítica aos desenvolvimentos "historicistas" que essa mesma idéia ganharia nas mãos de Marx e do marxismo. De um modo geral, uma divisão de trabalho emergiria dessa colaboração (não pretendida) entre Hayek e Popper, na qual o primeiro se encarregaria da construção positiva da idéia de Grande Sociedade, e o segundo, da desconstrução da escatologia marxista.

Em verdade, subjacentes quer à construção hayekiana quer à desconstrução popperiana estão as implicações cognitivas da nova concepção de ordem: em um

mundo que resulta de ações e intenções que não o visavam diretamente, o conhecimento individual revela-se extremamente limitado. Se as ações e decisões, de um modo geral, produzem repercussões que não foram antecipadas pelos atores, o estoque de conhecimento à disposição destes será sempre deficiente em relação à totalidade de conseqüências que suas ações se revelam ex post facto capazes de produzir. Este déficit cognitivo, chamemo-lo ignorância, confrontado com a ordem que não obstante resulta da interação dos atores, é a origem do problema que atrai e intriga tanto a Hayek quanto a Popper. Como é possível a ignorância gerar coordenação?

Hayek recorre a duas idéias auxiliares para elaborar a conexão entre ignorância e ordem. São elas (1) a noção de regras de conduta e normas sociais evolutivas que, paulatinamente e de modo não consciente, vão preenchendo as lacunas de conhecimento dos indivíduos de modo a coordenar suas ações, e (2) a idéia de efeito perverso, pela qual toda iniciativa de coordenação originada não em normas que evoluem gradualmente no tempo, mas em racionalismo construtivo, será punida pela produção do efeito inverso ao pretendido. A sociedade de mercado - em que a interação econômica é feita pelo mercado dentro dos marcos do Estado de Direito - seria uma instância da primeira noção, enquanto o Estado intervencionista (de qualquer tipo) seria uma instância da segunda.

Entretanto, e é aqui que o presente artigo se diferencia, não se pode a rigor afirmar que Popper endossaria essa conotação de ignorância, por assim dizer "passiva”, advogada por Hayek, e menos ainda as implicações especificamente políticas, sobre a esfera de intervenção governamental legítima na vida social e econômica, que celebram Hayek como um conservador. Na verdade, argumento neste artigo que, baseando-se na premissa de ignorância e na falibilidade do conhecimento e, portanto, descartando qualquer noção de determinismo histórico à Marx ou evolucionista à Hayek, Popper desenvolve uma filosofia política que reconhece no governo e na atividade política as esferas de ação cruciais na busca legítima por aperfeiçoamento da vida social. Essas conclusões são especialmente alvissareiras sobretudo para aqueles que crêem que o conhecimento no mundo social é falível 
mas que gostariam de ver bem fundamentadas suas esperanças (não deterministas) na possibilidade de reformas propositadas.

No que se segue, farei uma breve apresentação da abordagem de Hayek ao problema da ordem social, pensada a partir da premissa de ignorância como a condição de conhecimento dos atores, na parte 1. Apontarei ali uma importante ambigüidade, no que respeita às conclusões político-normativas que Hayek extrai desse ponto de partida epistêmico. De um lado, a ignorância interditaria aos atores sociais a possibilidade de reformar o mundo segundo suas vontades; de outro, essa mesma ignorância não incapacitaria Hayek de singularizar a ordem de mercado como a ideal e advogar intervenções reparadoras de desvios a ela, no que foi apelidado por Michael Oakeshott de “intervencionismo não-intervencionista”. Na parte 2, apresento a contribuição de Popper, a partir da revisão de seus trabalhos pertinentes, organizada da seguinte forma: na primeira seção, procuro discernir em seus textos mais propriamente filosóficos a conotação especificamente popperiana de ignorância, que emerge da defesa de um racionalismo crítico. Ao invés de propugnar a ignorância como uma irremediável carência de espírito que obrigaria os atores a seguir regras e normas vigentes de modo acrítico, a idéia popperiana de ignorância aparece fortemente associada à faculdade humana de invenção: aquilo que não se pode descobrir há que se inventar. Na segunda seção, investigo nos escritos de filosofia política de Popper, de que modo a concepção de ignorância como inventividade se traduz no ambiente social e político — sua tradução encontra-se nas idéias de tecnologia social e engenharia social. Finalmente, a terceira seção responde aos receios hayekianos de que alguma forma de tirania seguir-se-ia ao modelo de intervencionismo proposto: para Popper, o único intervencionismo que faz sentido, dada a premissa de falibilidade do conhecimento, é o intervencionismo democrático, aquele que aprende com os próprios erros e, com todos os defeitos, seria ainda a melhor garantia contra o dogmatismo no poder. Nessa seção, o intervencionismo econômico é justificado desde que se destine a ampliar a igualdade de liberdades substantivas na sociedade.

Popper parece, dessa forma, produzir, na contramão de Hayek, razões baseadas na própria falibilidade humana para tentativas de aperfeiçoamento do mundo social. Logo, ignorância recomenda intervenção.

\section{PARTE 1 HAYEK: ORDEM E ESPONTANEIDADE}

No pós-escrito ao seu magistral The Constitution of Liberty, intitulado "Por que não sou conservador", Hayek afirma que "where spontaneous change has been smothered by government control, [Liberalism] wants a great deal of change of policy" (Hayek [1960] 1993:399). Essa “política de espontaneidade” é emblemática do tipo de tensão freqüente entre intervencionismo e conservadorismo em seus escritos políticos. 
Por estranho que possa parecer, essa política é reivindicada por Hayek como o resultado natural de um argumento que se inicia em certos supostos factuais bastante convincentes a respeito do mundo social. É do famoso ensaio de 1767sobre a origem das instituições, do historiador Adam Ferguson, que Hayek vai retirar a observação histórica sobre a qual repousará toda a sua filosofia social: "[n]ations stumble upon stablishments, which are indeed the result of human action, but not the execution of any human design" (Apud Hayek, 1967:96, nota 1). De fato, no ensaio seminal "Scientism and the Study of Society", publicado entre os anos 19411944, Hayek desenvolve a observação de Ferguson com o propósito de criticar o que denomina "cientismo" social, uma atitude intelectual inadequada, que consistiria em transpor acriticamente o método das ciências naturais para as ciências sociais sem observar a natureza, digamos, fergusoniana de seu objeto: qualquer ação social (inclusive a do teórico debruçado sobre o fenômeno) produz resultados emergentes que solapam nossos esforços de controlá-los.

Deriva-se do cientismo social o retrato construtivista da ordem como resultado de planejamento e desígnio. Nada mais distante da verdade histórica, afirmaria Hayek. Em oposição a essa visão, Hayek propõe uma teoria social, de extração explicitamente fergusoniana, no ensaio de 1967, "The Results of Human Action but not of Human Design", no qual faz a ordem social brotar da interação entre indivíduos radicalmente ignorantes. A ignorância refere-se à impossibilidade de qualquer indivíduo alcançar uma perspectiva sinóptica, uma percepção do todo que resulta da interação entre as partes, e, pois, ao fato de estar o indivíduo essencialmente confinado ao conhecimento local. Na ausência de conhecimento global, a ação e a coordenação social podem parecer muito improváveis, porém elas seriam possibilitadas pela persistência de formas de conhecimento que, mesmo não dadas no nível da consciência dos indivíduos, estão presentes e são por eles utilizadas em seus intercursos ordinários: é o estoque cognitivo acumulado em regras práticas, instituições e modos de comportamento presentes nas sociedades, e que resultaria de lenta evolução através de experimentação espontânea. Ocorre que esse conhecimento social implícito não pode ser plenamente articulado pelos indivíduos que dele fazem uso, não apenas porque de fato não estão conscientes dele, mas porque não podem logicamente estar conscientes de todo o saber tácito que subjaz às suas ações, como Hayek explica detalhadamente no ensaio de 1962, "Rules, Perception and Intelligibility". Dessa feita, a ação social seria cognitivamente densa, mas a consciência do saber necessário a ela, bem como a força das intenções em produzir estados de coisas seriam muito limitadas. Pode-se, pois, concluir que nas mãos de Hayek a separação assinalada por Ferguson entre ação e intenção/desígnio recebe uma justificação de natureza sócio-epistemológica: é em virtude do limitado conhecimento consciente ou explícito à sua disposição que os atores não podem saber de antemão, nem tampouco controlar as conseqüências de suas ações. Apesar de eles ainda "fazerem" o mundo através de suas ações, o desígnio, a intervenção propositada, simplesmente não seria factível. Este fato representaria uma limitação não apenas para atores ordiná- 
rios mas também para os extraordinários, isto é, o cientista social e o reformador social ou o governo. Em outras palavras, por conta de regras de conduta e práticas sociais, a interação social torna-se fundamentalmente auto-governada.

A abordagem epistêmica de como surge a ordem inclui a emergência das leis, ao mesmo tempo em que circunstancia seu caráter. As leis, das quais o governo é o custódio, e que resultaram de experimentação prolongada, são de natureza tal a tornar o intercurso social menos imprevisível para os atores. Uma vez garantidas pelo governo, essas leis substituem o arbítrio e a discricionariedade que prevaleceriam em sua ausência, quando "the control of the essential data of an individual's action is in another man's hands" (Hayek 1960:139), por uma certa previsibilidade e generalidade. O governo tem, portanto, sua existência como custódio legitimada pela condição de proteger os governados de coerção por parte uns dos outros, coerção no sentido epistêmico de "control of essential data [for action]": todas as suas atividades - coercitivas ou não - acham-se justificadas desde que orientadas para a proteção da esfera de decisão privada dos indivíduos. Desse modo, o exercício de coerção legítima por parte do governo está limitado ao propósito de evitar coerção ilegítima, sob pena de ele próprio promover o caos epistêmico ao invés de minimizálo. Algumas exceções são todavia singularizadas por Hayek. Estas referem-se a atividades governamentais que, apesar de não conectadas com a evitação de coerção ilegítima, são suficientemente gerais e conhecidas de antemão de modo a elicitar a aprovação geral e a não afetar negativamente o horizonte de previsibilidade dos atores sociais. São elas as atividades de provisão de bens públicos, a garantia de um mínimo de subsistência como um seguro social contra riscos incalculáveis e um punhado de serviços sociais. Mas as atividades positivas do governo são concebidas como mero suplemento ao mecanismo de coordenação representado pelo mercado, cuja constituição inclui as características universalistas e preservadoras da liberdade individual requerida de leis que verdadeiramente reduzem a incerteza. Essas idéias começam a ser desenvolvidas em The Road to Serfdom $(R S)$, especialmente no capítulo IX: "Security and Freedom", mas encontram-se já maduras em The Constitution of Liberty $(C L)$, especialmente no capítulo 9: "Coercion and the State".

Não obstante, o perfectibilismo, que tanto repele a Hayek, inadvertidamente penetra no seu próprio sistema. De fato, é quando detalha sua visão do escopo das atividades positivas do governo que as dificuldades proliferam. No âmbito do RS, Hayek já se mostrara desconfortável com relação aos privilégios que uma posição política de defesa irrestrita do laissez-faire poderia vir a acomodar - é possivelmente sua sensibilidade socialista de mercado de então que o faz declarar que "there is [...] all the difference between deliberately creating a system within which competition will work as beneficially as possible and passively accepting institutions as they are" (Hayek [1944] 1979:17). Mais tarde, porém, na medida em que se torna menos crítico das sociedades capitalistas e mais convencido não apenas da força causal da hipótese de ordem espontânea, como também de seu caráter virtuoso 
como veículo de ideais, sua preocupação e atitude em relação à intervenção vão se tornando ao mesmo tempo mais firmes ${ }^{1}$ e problemáticas. Por um lado, arranjos sociais que se tornaram mais ricos e populosos, como os que existem em sociedades liberais orientadas para o mercado, provaram, mediante esses resultados, ser moralmente superiores aos outros, confirmando o acerto de suas regras e leis que teriam evoluído espontaneamente. A partir dessa convicção, Hayek procura justificar todo tipo de intervenção estatal voltada para a restauração da "espontaneidade" interrompida. Por outro lado, contudo, esforços voltados para a alteração do sistema de regras incorporadas nessas sociedades, visando especialmente algum patamar de "justiça social", estariam destinados a se perverter e a destruir o mecanismo espontâneo responsável pela produção de sociedades bem sucedidas, e por esse motivo seriam condenados. Em conseqüência, a concepção evolucionária de lei, cujos fins estão em aberto, e que seria recomendada pela visão epistêmica de ignorância radical de Hayek, cederia vez a um evolucionismo social, isto é, um determinismo social de leis de evolução, as quais, uma vez reconhecidas, deveriam ser impostas pela ação governamental, com toda a atividade legislativa positiva necessária. ${ }^{2}$ Essa atitude, além de produzir o paradoxo prático de uma intervenção anti-intervencionista assinalado por Oakeshott (1974), possui uma implicação ainda mais perturbadora, no presente contexto, ao alinhar Hayek com a tradição construtivista da economia política representada sobretudo por Quesnay e os fisiocratas, a qual rejeita por razões cognitivas. Esse alinhamento afasta-o precisamente da tradição mais sóbria da qual Hayek reivindica herança, a do ceticismo fergusoniano e smithiano. ${ }^{3}$

A atitude de Hayek com relação à atividade governamental, por conta do problema do conhecimento limitado, é, dessa forma, ambígua. Por um lado, na medida em que as conseqüências das ações não são plenamente antecipáveis, recomenda-se mínima dose de intervenção governamental, sob pena de promoção de tirania e de degeneração da própria ordem. Por outro, as conseqüências de intervenções de certo tipo serão destrutivas, pois põem em risco um futuro melhor do qual se tem pré-ciência (pode-se perguntar, como?), e então a contra-intervenção e o governo positivo (franca legislação e políticas públicas), ou seja intervenção de outro tipo, urgem (mas como podem ser imunes ao problema da ignorância quanto às conseqüências?). Como decidir entre intervenções boas e más sem primeiro estabelecer a possibilidade epistêmica de qualquer intervenção? Sobretudo, como fazê-lo sem incorrer em algum tipo de determinismo social?

\footnotetext{
${ }^{1}$ Ver Hayek [1960]1993, esp. cap. 15 e o Pós-Escrito, e também Hayek 1988.

${ }^{2}$ Ver Kerstenetzky (2000) e sua distinção entre um Hayek evolucionário e outro evolucionista.

${ }^{3}$ Em The Counter-revolution of Science, p. 19, os fisiocratas são apresentados como representantes precoces da tentativa de tratar os fenômenos sociais "scientistically", enquanto a teoria social de Smith é reconhecida como um dos "great achievements of the [eighteenth] century in the theory of the social sciences... whole free from [scientism]”.
} 
Conforme veremos na próxima parte, Popper produz uma resposta peculiar para esses dois problemas.

\section{PARTE 2 POPPER EM BUSCA DE UM MUNDO MELHOR}

Karl Popper, em contraste com Hayek, permanece em sua filosofia política um defensor do intervencionismo, sem em princípio impor limites à escala ou ao escopo das reformas sociais pretendidas. De modo significativo para os meus propósitos neste artigo, Popper apresenta o seu ponto de vista otimista a partir de uma visão bem estabelecida sobre a precariedade do conhecimento humano, de modo a produzir a relação positiva entre ação e desígnio humano negada por Hayek.

$\mathrm{Na}$ verdade, como mostrarei nesta parte, nas mãos de Popper, o ativismo político bem como o intervencionismo democrático aparecem como a resposta cética apropriada à precariedade do conhecimento humano, basicamente por conta de dois entendimentos do que seja a condição de ignorância - potencial para invenção e indeterminação social. Para Popper, a relação entre conhecimento limitado e desígnio desenrola-se no terreno das possibilidades (e não de necessidades pré-determinadas), da política, portanto. Pois mesmo não estando disponível uma técnica política - um conjunto de instruções articuláveis para se atingir propósitos abrangentes no mundo social - é possível substituí-la por uma tecnologia social, derivada de exercício de imaginação crítica; e mesmo não sendo previamente conhecido o propósito comum que uma sociedade deve perseguir, a deliberação democrática sobre fins a realizar sempre é possível, e mesmo necessária. Por conta, portanto, da ignorância de meios e fins, a política, longe de ser uma dimensão superficial da vida social enquanto tal, torna-se o terreno crucial.

Nas próximas três seções, explicitarei a estratégia otimista de Popper em dois tempos. Inicialmente, oferecerei um entendimento do peculiar ceticismo cognitivo de Popper, elaborando os três temas que nele aparecem entretecidos, quais sejam o racionalismo limitado ou crítico, a tradição e a invenção. Passo, então, nas duas seções seguintes, a traçar as implicações dessas noções para a reforma institucional e o governo, e indicar os contrastes relevantes com Hayek.

\section{1) Os recursos de um racionalismo limitado}

Em três passos, vou apresentar o argumento epistêmico:

\section{Passo 1: Que racionalismo, se algum, é logicamente aceitável?}

Examinando detidamente a crítica ao racionalismo, empreendida por conservadores como o historiador inglês Michael Oakeshott, Popper rejeita, no ensaio "The Defence of Rationalism", de 1945, a possibilidade de um "racionalismo compreensivo" - isto é, a atitude de não se aceitar nenhuma proposição que não esteja amparada quer em argumento, quer em evidência. Essa atitude, pondera ele, 
não está ela mesma baseada nem em argumento nem em evidência, conseqüentemente o racionalismo compreensivo seria logicamente insustentável. O racionalismo, se algum for possível, deve repousar sobre uma decisão pré-racional, não há escapatória: "no rational argument will have an effect on a man who does not want to adopt a rational attitude" (Popper [1945]1987:131); ademais, argumentos e evidências são dependentes de conhecimento prévio, de opiniões ou "pressupostos", eles próprios não ancorados em argumento e evidência. Não obstante, se o racionalismo for entendido como a atitude voluntária de se proceder à crítica sistemática, à luz da lógica e da experiência, de conhecimento recebido, tanto a decisão préracional quanto os nossos pressupostos não conflitariam intrinsecamente com ele; ao contrário, estes ofereceriam a motivação e o material sobre o qual o racionalista pode operar. Nesse caso, o racionalismo tornar-se-ia coerente precisamente ao reconhecer seus limites.

É, pois, o racionalismo ilimitado que é logicamente deficiente, não aquele que reconhece suas limitações, sua origem em preferências, sua dependência de pressupostos. O racionalismo torna-se então um método - crítico - de avaliação e aquisição de conhecimento, sempre falível. A rejeição ao racionalismo compreensivo não implicaria rejeição ao racionalismo tout court.

Passo 2: A relação entre razão e tradição.

No ensaio "Towards a Rational Theory of Tradition", em que busca fundamentar a possibilidade das ciências sociais, Popper examina a antinomia tradição versus razão, para concluir que a relação logicamente saudável entre as duas é a de cooperação. As tradições são apresentadas por ele como "sistemas de referência" ou "ordens", ou ainda "lógica da situação", de todo modo indispensáveis para a ação racional, seja ela a ação social ordinária seja a ação visando a reformas sociais.

As tradições desempenhariam no mundo social um papel semelhante aos mitos na filosofia clássica, de nutriente cognitivo a ser criticamente processado, de "pressupostos". Por um lado, às tradições é garantida uma certa prioridade ou precedência com relação à razão: "It is not possible for you to act rationally in the world if you have no idea how it will respond to your actions. Every rational action assumes a certain system of reference which responds in a predictable, or partly predictable way" (Popper [1949] 1987:131). Mas, por outro lado, as tradições aí estão para ser escrutinadas e criticadas, não dogmaticamente consumidas. Elas nos oferecem "something upon which we can operate; something that we can criticize and change. This point is decisive for us, as rationalists and social reformers" (Idem, ibidem).

Numa jogada mais arriscada, Popper além de discernir essas funções construtivas das tradições também nos revela sua natureza artificial: elas seriam de algum modo inventadas, dando como evidência disso o próprio racionalismo, isto é, a tradição, inventada pelos filósofos gregos, de examinar criticamente as tradições. Com esse lance, Popper ao mesmo tempo desnaturaliza e desidealiza as tradições, e su- 
gere uma compreensão alternativa, racional (ainda que não compreensiva) delas. Explico a seguir.

\section{Passo 3: Invenção de tradições.}

$\mathrm{Na}$ obra propriamente filosófica de Popper, há duas instâncias da sugestão de que podemos inventar tradições, no sentido de sistemas de referência ou ordens. A primeira delas aparece em Objective Knowledge na forma do extensamente debatido "Mundo 3", o mundo das teorias e conjecturas, dos problemas e também das instituições. Esse mundo emerge de uma peculiar forma de auto-transcendência, como um resultado extravagante de práticas intencionais de busca de aquisição de conhecimento, de resolução de problemas ou de aprendizado, por parte de indivíduos e grupos: "The process of learning [...] is always fundamentally the same. It is imaginative criticism. This is how we transcend our local and temporal environment by trying to think of circunstances beyond our experience: by criticizing the universality, or the structural necessity, of what may, to us, appear [...] as the 'given' or as a 'habit'; by trying to find, construct, invent new situations - that is test situations, critical situations; and by trying to locate, detect, and challenge our prejudices and habitual assumptions" (Popper 1974:147/148). Nessa chave de leitura, o racionalismo crítico, ele mesmo originário de um esforço inventivo de autotranscendência, não se confinaria à atitude de efetuar testes de coerência no interior de situações lógicas dadas. Ele seria entendido como um esforço intelectual, um engajamento da imaginação pelo qual o sujeito seria capaz de gerar o próprio quadro de referência ou "situações-teste" que então se prestariam ao teste de coerência. Que esses objetos ou mundos inventados passam a ter vida própria não anula o fato de que fomos nós que os produzimos. Chamarei esse efeito excedente da atividade humana de resolução de problemas, de "externalidade da racionalidade" (tomando-se racionalidade no sentido da habilidade de exercer crítica imaginativa com o propósito de resolver problemas).

A segunda instância da "inventividade dos ignorantes", que possui implicações mais diretas para o problema da constituição do mundo social e da intervenção possível sobre ele, comparece em In Search of a Better World, de 1984. Em meio à argumentação por abordagens alternativas à noção evolucionária de seleção, Popper indica que a seleção de maneiras de resolução de problemas normalmente envolve a freqüentemente negligenciada habilidade dos organismos de criar nichos, isto é, circunstâncias que tendem a corroborar as soluções que eles encontram em sua busca por um mundo melhor ${ }^{4}$ (Cf. Popper 1992: 13/14). Essa com-

\footnotetext{
${ }^{4}$ Lemos em Popper, op. Cit., pp.13/14 (ênfase minha), a seguinte qualificação à teoria da evolução: “My new optimistic interpretation [of Darwin's theory of evolution] stresses (as does Bergson) the activity of all living creatures. All organisms are fully occupied with problem-solving. Their first problem is survival. But there are countless concrete problems that arise in the most diverse situations. And one of the most important problems is the search for better living conditions: for greater freedom; for a better world. According to this optimistic interpretation, it is through natural selection and (we may suppose)
} 
preensão do mecanismo de seleção é estranha ao tratamento que Hayek dá ao tema, com sua ênfase típica no papel das circunstâncias externas que fogem ao controle humano. ${ }^{5}$ A transposição da proposição de Popper para o mundo social é deixada ao encargo do leitor, mas a linguagem é suficientemente sugestiva: viver é solucionar problemas, em busca de um mundo melhor. De fato, a hipótese popperiana de nichos encontra farta evidência em interações no mundo social, como ilustrado pela miríade de instâncias de poder de mercado, e ações coletivas de um modo geral, configurando-se em ações sobre o ambiente que parecem afetar a chance de sucesso de indivíduos e grupos. A estratégia de "construção do ambiente" domesticaria a incerteza ao elevar a previsibilidade local, e criar uma oportunidade, ou mesmo uma demanda moral, para a intervenção do Estado, como veremos na última seção. Essa segunda instância de invenção sugere que, em acréscimo à fabricação do ambiente (e a conseqüente geração de desenvolvimentos não pretendidos), como nas externalidades da racionalidade, os atores sociais teriam a habilidade de controlá-lo pelo menos até certo ponto. Designarei esse segundo efeito da ação humana de "internalização das circunstâncias".

Ao fim e ao cabo, mesmo encapsulando a razão em uma tradição - a tradição de crítica das tradições —, Popper vê a interação entre razão e tradição não apenas como limitação recíproca, na qual a razão escrutinaria a tradição ao mesmo tempo em que operaria no interior da lógica desta. Mas ao reconhecer que as tradições podem ser inventadas, Popper concede mais liberdade ao jogo razão-tradição, deixando espaço para a criatividade (como nas externalidades da racionalidade) e para a construção do ambiente (como na internalização das circunstâncias). A tradição fica assim liberta do jugo da reificação, e uma teoria "racional" da tradição torna-se possível (entre aspas porque refere-se à peculiar compreensão de racionalismo proposta por Popper).

A aposta de Popper parece ser, pois, que não apenas muito do mundo social é um resultado extravagante de ações intencionais (como queria Ferguson, como insiste Hayek), mas também que a limitação de conhecimento a que estamos submetidos nos deixa como única alternativa a estratégia cognitiva de segunda mão, peculiar a ignorantes racionais, de aprender com os erros e, sobretudo, inventar

through an external selection pressure that a strong internal selection pressure comes into being at a very early stage; a selection pressure exerted by the organisms upon their environment. This selection pressure manifests itself as a kind of behaviour that we may interpret as searching for a new ecological niche. Sometimes it is even the construction of a new ecological niche [...] the organisms seek new niches, even without having undergone any organic change themselves; and they mutate later as a result of the external selection pressure, the selection pressure of the niche that was actively chosen by them."

\footnotetext{
${ }^{5}$ Hayek trata a seleção como um mecanismo cego que corrobora ou elimina regras de conduta de acordo com sua habilidade em incrementar a adaptabilidade do grupo a circunstâncias externas que mudam de modo não previsível: "systems of rules will develop as wholes, selection process of evolution will operate on the order as a whole: so a new rule of individual conduct which in one position may prove detrimental, may in another prove to be beneficial” (Hayek, 1967:71).
} 
o que não pode ser descoberto, eventualmente aumentando a chance de sermos bem sucedidos nas mudanças que venhamos a propor ou nas tentativas de solucionar problemas.

Nosso próximo problema é: como essa interpretação otimista de nossa condição epistêmica se transpõe em defesa da intervenção?

\section{2) Tecnologia social, engenharia social}

Em The Poverty of Historicism, Popper assevera as virtudes epistêmicas das reformas institucionais ou "engenharia social" com as seguintes palavras: "The social sciences have developed very largely through the criticism of proposals for social improvements[...], through attempts to find out whether or not some particular economic or political action is likely to produce an expected, or desired, result" (Popper [1957] 1997: 58). Ele está, contudo, ciente de que o termo "engenharia social" levantará objeções, sobretudo por parte de Hayek (idem, ibidem). O obstáculo parece ser o problema do conhecimento limitado. Como a engenharia social seria possível, dada a restrição ao conhecimento consciente apontada por Hayek? Popper reconhece a dificuldade, mas não compra as conclusões políticas de Hayek, em uma divergência entre eles que nunca se explicita publicamente, confinando-se à correspondência entre ambos, ou com terceiros. ${ }^{6}$ Para Popper, a engenharia social torna-se possível graças a uma forma modificada de conhecimento, mais modesta do que o conhecimento certo, mas nem por isso ineficaz - a tecnologia social. A tecnologia social é uma hipótese de conhecimento que equivale a uma auto-consciência da limitação do conhecimento: é um conjunto de leis condicionais que pode ser instrumentalizado para intervir no mundo social. As leis tecnológicas seriam leis que articulam a lógica da situação presente em partes do mundo. Contudo, a consciência da limitação do conhecimento recomendaria uma conotação de tecnologia por assim dizer negativa: enquanto no mundo dos objetos físicos a tecnologia indicaria aquilo que não pode ser alcançado - p. ex.: vo-

\footnotetext{
${ }^{6}$ De fato, Hayek e Popper parecem ter discordado sobre vários assuntos, ainda que não publicamente. As diferenças tornam-se claras a partir da análise da intensa correspondência entre ambos. Esta incluiria a divergência quanto ao laissez-faire e o ideal de justiça social, que para Hayek era um erro conceitual, mas não para Popper, que muito o prezava (veja as cartas de Popper para Hayek de 6 de maio de 1946 e de 22 de maio de 1946, no Hayek Archive 44-1, cf. Shearmur, 1996). Popper também mostra preocupação com a desigualdade econômica, a interferência de interesses econômicos na política, o poder dos monopólios, e afirma acreditar que "freedom cannot be saved without improving distributive justice”, em uma carta a Carnap de 17 de novembro de 1946 (Popper Archive 282-24), cf. Shearmur, op. Cit. Em carta a Weimer, de 16 de janeiro de 1983, Hayek, por sua vez, desaprova a visão política de Popper, e expressa "the view that Popper remained too much of an economic interventionist" (Shearmur, 1996, p.35). No presente artigo, vou me diferenciar da posição assumida por Shearmur, em seu livro, sobretudo de sua acusação a Popper de não levar suficientemente a sério, ao propor instituições de engenharia social, "the character of the material upon which it is working" (Introduction). Em minha interpretação, Popper leva isso bastante a sério, ao tentar esclarecer a natureza do problema, como espero deixar claro a partir da discussão empreendida na presente seção.
} 
cê não pode carregar água com uma peneira - a tecnologia social, ao se aplicar a um mundo resiliente, trata de buscar aquilo que não pode ser alcançado "without causing some repercussions which are undesirable from the point of view of the ends aimed at" (Idem, ibidem). Em conseqüência, o reformador social deve interessar-se vivamente na antecipação e na administração dessas repercussões, sempre que possível, de modo a não pôr a perder seus objetivos, bem como manter-se bem informado ex post facto dos efeitos emergentes da intervenção que não foi capaz de antecipar. Na verdade, as reformas tentativas são o melhor modo de se adquirir conhecimento sobre o mundo social, sobre sua reatividade, pois são experimentações que possibilitam ao reformador corrigir suas suposições. Dessa forma, a tecnologia social combina privilegiadamente com a crítica acurada as duas hipóteses centrais sobre a constituição epistêmica do mundo social para a qual contribui a das externalidades da racionalidade (isto é, repercussões não desejadas ensejadas pela intervenção) e a de internalização das circunstâncias (isto é, a possibilidade de mudança dos parâmetros dentro dos quais decisões são tomadas, através de desenho institucional).

Em resumo, para se fazer política construtiva, o suposto cognitivo de tecnologia social seria suficiente; aliás ganha-se conhecimento desse tipo mediante a política construtiva. E mesmo uma intervenção anti-intervencionista à Hayek repousaria sobre alguma forma de tecnologia social, na medida em que faz previsões: "to assert that interventionism makes matters worse is to say that certain political actions would not have certain effects - to wit, the desired ones," ou ainda: "you cannot achieve such and such ends without such and such concomitant effects" (Popper 1985: 306).

Não obstante, a restrição ao conhecimento de fato imporia um limite à intervenção, salienta Popper, semelhante em espírito ao que impõe ao racionalismo ilimitado: ela impede as reformas de tipo holista, como as contidas no plano total do engenheiro utopista. De certo modo, este está para a intervenção em posição incontinente análoga à do racionalista compreensivo em relação à razão, isto é, como alguém que não reconhece suas limitações, colocando em risco a sensatez de sua própria posição. O plano total do utopista estaria condenado a degenerar em improvisação, por conta das repercussões não pretendidas de suas ações, "continually [leading him] to do things which he did not intend to do" (Popper [1957] 1997: 68/69). Deve-se, contudo, notar que Popper exclui esse tipo de intervenção justamente porque deseja assegurar-se de que mesmo sob a condição de ignorância as reformas pretendidas possam ter sucesso. O gradualismo nas reformas seria necessário porque se apresentaria como o único método eficaz mediante o qual ignorantes racionais podem aprender com seus próprios erros, fazendo seu percurso "step by step, carefully comparing the results expected with the results achieved, and always on the look-out for the unavoidable unwanted consequences of any re- 
form" (Idem, ibidem) ${ }^{7}$. O reformador total (o revolucionário, o planejador coletivo) não consegue acompanhar as repercussões indesejadas de seu plano e corrigi-las adequadamente. Na verdade, seria o planejador utopista o verdadeiro alvo da crítica hayekiana quanto à impossibilidade de uma mente sinóptica, não o reformador social incremental.

$\mathrm{Na}$ visão de Popper, portanto, a intervenção gradual é não apenas essencial para abrir o horizonte de conhecimento dos atores sociais, como a sonda de que dispõem os ignorantes racionais, mas também aparece bem fundamentada cognitivamente. De fato, enquanto sonda, as reformas criam a oportunidade epistêmica para mais reformas, dando origem a um ciclo benigno intervenção-conhecimento-intervenção, em que instituições uma vez reformadas ou criadas alargariam o horizonte de situações lógicas e repercussões não antecipadas associadas, desvendando novas oportunidades para reformas institucionais.

Permanece, entretanto, a dúvida quanto à desejabilidade de um intervencionismo sem fim, pelo crescente poder conferido ao Estado nesse processo. Popper não parece alterar-se diante desse problema: em acréscimo à recomendação de um intervencionsimo prudente (não holista) e de um humanitarismo genérico, como em sua ética da tolerância, Popper não considera a condição de conhecimento limitado restritiva quer em termos de escala, quer de escopo da intervenção proposta (Cf. Popper [1957] 1997: 69). O contraste com Hayek aqui é flagrante, sobretudo quando o escopo é justiça distributiva, para Hayek um contra-senso, conforme atesta a obra de toda a sua vida (Hayek 1944, 1960, 1976, 1988, 1994). Popper é explícito na não exclusão de qualquer propósito (condicionada pelas duas exceções mencionadas acima): além de reformas constitucionais, intervenções com propósito redistributivo poderiam ser bem-vindas, como uma série de reformas graduais "towards a greater equalization of incomes. [...] Piecemeal methods may lead to changes in what is usually called the "class structure of society" (Popper [1957] 1997: 68). Como Popper concilia essa posição político-normativa com seu argumento epistêmico? Como ele lida com o desafio do pluralismo moral e o risco, vislumbrado por Hayek, de tirania? Em outras palavras, além de cognitivamente exeqüível, será que a engenharia social advogada por Popper é desejável?

\section{3) Intervencionismo democrático}

Deve-se notar que o ponto de partida de Popper, tanto na filosofia da ciência quanto em sua filosofia social, é anti-determinista. Toda forma de determinismo

\footnotetext{
${ }^{7}$ Não é, portanto, por conta do conservadorismo de Popper que a reforma gradual é proposta, mas justamente pelo reformismo e perfectibilismo que ele endossa. Estou aqui discordando da ênfase que, de um modo geral, a tradição de intérpretes de Popper coloca na distinção entre um "Popper revolucionário" na filosofia da ciência, e outro conservador, na filosofia política. Ver, por exemplo, Stokes (1998) e Vernon (1976).
} 
social é descartada em sua "busca por um mundo melhor", pois dada a ignorância como nossa condição básica de conhecimento, não se pode determinar de antemão quais devem ser os propósitos últimos da sociedade. Essa posição aparece com clareza na crítica de Popper a Marx em The Open Society, em sua rejeição ao historicismo e ao determinismo econômico por meio de argumentos falibilistas. E se por um lado, Popper subscreve à teoria social de Marx e à crítica "moral" que este faz ao capitalismo - isto é, que a "exploração econômica" e a liberdade meramente "formal" que florescem no "unrestrained capitalism" seriam erros absolutos - por outro, ele julga, contra Marx, ser a política a dimensão relevante para a correção desses defeitos. ${ }^{8}$ A política, longe de ser a expressão superficial do subterrâneo drama econômico que se desenrolaria a despeito das decisões humanas, seria a verdadeira "infraestrutura": ela revela-se como o espaço crucial onde meios e fins seriam decididos, já que não estariam pré-determinados. E, de novo, dado nosso conhecimento imperfeito dos assuntos do mundo social, o único tipo de intervenção política recomendável seria o democrático, isto é, intervenção submetida à disciplina democrática da deliberação - com transparência de propósitos e processos, crítica aberta e a possibilidade de mudança à luz da crítica (Popper [1962] 1971, v. 2, cap. 17; cap. 18, nota 9, p. 335).

Contudo, seria possível contra-argumentar que os fins, digamos, morais recomendados por Popper, como o término da "exploração econômica" e por um sentido mais substantivo de liberdade, em linha, segundo sua interpretação, com a crítica de Marx ao capitalismo, não estariam suficientemente fundamentados de modo a vencer a objeção típica de Hayek de que sua imposição seria tirânica. Por que selecionar estes propósitos em detrimento de outros, e mobilizar o potencial interventor do Estado para a sua promoção? A resposta engenhosa de Popper vem junto com a articulação de sua concepção de democracia e de tirania. Como vimos, o ponto de partida de Popper é a democracia, que ele justifica por razões epistêmicas (já que somos todos ignorantes temos que criar condições políticas para aprender com nossos erros). A tirania seria uma forma de dogmatismo no poder para a qual a democracia seria o remédio. Entretanto, o poder não é só político, seu controle do qual requerendo a prestação de contas típica de democracias políticas, mas também é indiretamente econômico, podendo ser apropriado pela força econômica de atores específicos. Essa situação também requereria restrição, alguma forma de democracia econômica, que seria buscada mediante a intervenção do Estado.

Elaborando um pouco mais, a resposta popperiana à dúvida cética hayekiana parece afirmar que se o risco de tirania é de todo um impedimento para o estabelecimento de propósitos a serem perseguidos socialmente, ele é mais iminente pa-

\footnotetext{
${ }^{8}$ Ver Popper [1962] 1971, v. 2, capítulo 17: “The Legal and the Social System”, onde Popper estende seu apoio à crítica, por assim dizer, moral de Marx ao capitalismo, apesar de rejeitar a teoria política da "impotence of politics" deste.
} 
ra desatentos "intervencionistas anti-intervenção" do que para intervencionistas democráticos:

a) Se é de todo um impedimento... Excluindo-se o caso de governo autoritário, a tirania seria uma ameaça real apenas em concepções soberanistas de democracia, onde esta seria entendida como a regra da maioria, ou o governo do povo, isto é, a imposição incondicional, então dogmática, da vontade da maioria. Essa, entretanto, não é a visão de Popper, embora pareça ser a concepção de democracia que Hayek possui e que o leva a criticá-la duramente. ${ }^{9}$ Para Popper, ao invés de ser o arranjo político desenhado para implementar o politicamente certo, "a vontade do povo", a democracia seria menos ambiciosamente concebida como o arranjo destinado a evitar o pior: para ele, a perseverança no erro por parte dos poderosos. ${ }^{10}$

Democracia envolveria, de modo crucial, a prestação de contas: eleições periódicas, os mecanismos constitucionais de pesos e contrapesos, a possibilidade de demissão do governante sem banho de sangue; significaria, nessa perspectiva, "political control of the political power of the rulers by the ruled". Caminhos errados não seriam obliterados, pois esse feito seria impossível de se alcançar, mas pelo menos o pior seria evitado, isto é, a impossibilidade de se corrigirem os erros ou de se aprender com eles. ${ }^{11} \mathrm{E}$ mesmo se o pior assim definido não puder ser evitado, como quando a democracia elimina a si mesma através do voto, isso detrataria menos a democracia e mais a cultura política que se revelaria tolerante à tirania, ao fim das contas apenas demonstrando que não há um "foolproof method of avoiding tyranny". ${ }^{12}$

Dessa maneira, outra simetria foi aqui alcançada em relação ao racionalismo limitado, em acréscimo ao reformismo limitado: a democracia seria a forma de governar mais apropriada à condição de conhecimento limitado, uma vez que, frente às alternativas, ela oferece o maior grau de imunização contra o dogmatismo no poder. b) ... é um problema maior para a variante de intervencionismo anti-intervencionista. Em uma concepção mais densa de democracia, esta seria para Popper também "the political control of the economic power of the ruled by the rulers". A existência do que ele denomina "semi-political organizations", como

\footnotetext{
${ }^{9}$ Ver, por exemplo, a crítica de Hayek à democracia em seu trabalho seminal [1938-1939] 1997. Ver ainda o ensaio "Whither Democracy?”, em Hayek 1978, especialmente p. 152-3.

${ }^{10}$ Nas palavras de Popper: "He who accepts the principle of democracy is therefore not bound to look upon the result of democratic vote as an authoritative expression of what is right. Although he will accept a decision of the majority, for the sake of making the democratic institutions work, he will feel free to combat it by democratic means, and to work for its revision" (Popper [1962] 1971, v. 1: 125).

${ }^{11}$ Ver, idem, ibidem, capítulo 7, especialmente p. 125.

${ }^{12}$ Idem, ibidem. Nas palavras de Popper: "the various equalitarian methods of democratic control [...] are to be considered as no more than well-tried and, in the presence of a widespread traditional distrust of tyranny, reasonably effective safeguards against tyranny". Ênfase minha.
} 
"monopolies, trusts and unions", e de desigual poder de barganha de ricos e pobres em seus encontros no mercado de trabalho, reduz "the freedom of the market to a fiction". ${ }^{13}$ A consideração daquelas entidades como parte do ambiente político, em acréscimo às desigualdades reais de liberdade econômica, sugeriria que existem outros lugares, além das instituições políticas propriamente ditas, de poder ameaçador, tirânico, demandando controle democrático. Essa situação corresponderia ao cenário hipotético de um "unrestrained capitalism”, o qual exemplificaria o que Popper chama de "paradox of freedom" - liberdade em demasia levando à opressão, não apenas do forte sobre o fraco (este excesso poderia ser contido pelo Estado de Direito à Hayek), como também econômica, do rico sobre o pobre, onde "the economically strong is still free to bully one who is economically weak, and rob him of his freedom" ${ }^{14}$ o que só poderia ser tratado com um "political remedy", a intervenção democrática: "we must construct institutions for the democratic control of economic power, and for our protection from economic exploitation". ${ }^{15}$ A intervenção democrática na vida econômica seria assim justificada como antídoto à desigualdade de liberdades econômicas. E mesmo levando ao incremento do poder do Estado, o próprio monitoramento democrático ou a democracia em sua concepção menos densa, seria a força equivalente contrária ótima. ${ }^{16}$ A verdadeira tirania seria, pois, o dogmatismo no poder, incorporado seja no governante autoritário, seja no poder não controlado de organizações semi-políticas. Mas os intervencionistas anti-intevencionismo estariam negligenciando essa dimensão de tirania, o poder ameaçador das organizações de mercado. Ou talvez considerem ser esta dimensão de poder um mal menor? Nesse caso, eles estariam a dever uma justificação da ordem "espontânea” de mercado, e o intervencionismo que julgam necessário para restaurá-la ou conservá-la, para defender-se de modo consistente contra a acusação que lançam aos demais intervencionistas de favorecerem algum tipo de "tirania de finalidades". E se não produzirem tal justificação, encontram-se vulneráveis à acusação de praticar alguma forma de determinismo social.

É por conseguinte contra duas versões de determinismo social (econômico) que o intervencionismo democrático popperiano, com sua primazia da política, se insurge: os fetichismos marxista, de uma História redentora, e hayekiano, de uma ordem de mercado como o melhor dos mundos possíveis. Nessa segunda volta do parafuso do argumento da ignorância, Popper nos surpreende com o alcance construtivo de sua epistemologia social negativa.

\footnotetext{
${ }^{13}$ Popper [1962] 1971, v. 2, nota 26:348.

${ }^{14}$ Idem, ibidem, v. 2:124.

${ }^{15}$ Idem, ibidem, v. 1:129.

${ }^{16}$ Idem, p. 130.
} 


\section{CONCLUSÃO}

Um exame da obra de Popper desvela uma abordagem mais otimista à relação entre ignorância e intervenção do que a tornada célebre por Hayek, avessa à intervenção (exceto àquela que venha a restaurar a "espontaneidade" dos mercados). A intervenção do Estado na vida econômica estaria interditada, para Hayek, em virtude da ignorância que persiste no mundo social e que impede o conhecimento e controle de todas as suas conseqüências. Além de não-exeqüível, ela seria indesejável, dada a inexistência do conhecimento sobre fins comuns que a intervenção deveria perseguir; a persecução de quaisquer fins outros que não os implícitos na ordem liberal (a qual reconheceria a irredutível pluralidade de finalidades na sociedade) seria necessariamente tirânica. $\mathrm{O}$ argumento de Popper corrige a inconsistência lógica implícita na posição hayekiana em favor de um intervencionismo anti-intervenção, e apresenta razões de ordem não apenas lógica mas também político-moral (anti-tirania) para a intervenção do Estado na vida econômica das sociedades contemporâneas, para além da moldura mínima do Estado de Direito. Baseado na noção de conhecimento limitado ou falível, Popper sustenta não apenas a possibilidade mas a oportunidade de intervenções planejadas sobre a ordem econômica em artefatos metodológicos como o racionalismo crítico, a tecnologia social, a engenharia gradual (piecemeal) e o intervencionismo democrático. Estes seriam substitutos de suas versões mais radicais, porém não disponíveis num mundo imerso em ignorância, quais sejam, o racionalismo compreensivo, o conhecimento certo, a engenharia total e o intervencionismo coletivo. Nas mãos de Popper, a ação social parece contar irrevogavelmente com as intervenções: dada a ignorância, o mundo social só se dá a conhecer quando se o modifica.

\section{REFERÊNCIAS BIBLIOGRÁFICAS}

Hayek, F. A., ([1938-1939]1997), "Freedom and The Economic System”, in F. A. Hayek, Socialism and War.

(1941-1944) "Scientism and the Study of Society", in F. A. Hayek (1979a), The CounterRevolution of Science.

. ([1944]1979), The Road to Serfdom, London and Henley: Routledge \& Kegan.

. ([1952]1979a), The Counter-Revolution of Science - Studies on the Abuse of Reason,

Indianapolis: Liberty Press.

([1960]1993), The Constitution of Liberty, London: Routledge \& Kegan Paul.

(1967), Studies in Philosophy, Politics and Economics, London: Routledge \& Kegan Paul.

. ([1962]1967), "Rules, Perception and Intelligibility", in Hayek, F.A., (1967), Studies in

Philosophy, Politics and Economics.

. (1967), “The Results of Human Action but not of Human Design”, in F. A. Hayek, Studies

in Philosophy, Politics and Economics.

. (1976), Law, Legislation and Liberty, London: Routledge \& Kegan Paul.

. (1978), New Studies in Philosophy, Politics, Economics and the History of Ideas, Chicago:

The University of Chicago Press. 
Hayek, F. A. ((1988), The Fatal Conceit - The Errors of Socialism, The Collected Works of F. A. Hayek, vol. 1, ed. W. W. Bartley, Chicago: The University of Chicago Press. . (1994), Hayek on Hayek: an autobiographical dialogue, ed. Stephen Kresge and Leif Wenart, Chicago: University of Chicago Press.

Kerstenetzky, C. L., (2000), “Hayek: The Evolutionary and The Evolutionist”, Rationality and Society, 12(2). Miller, D., (1987), A Pocket Popper, Fontana Press.

Oakeshott, M., (1974), Rationalism in Politics and other essays, London: Methuen \& Co Ltd. Popper, K. R., ([1945]1987), “The Defence of Rationalism”, in D. Miller, A Pocket Popper. • ([1949]1987), “Towards a Rational Theory of Tradition”, in: D. Miller, A Pocket Popper. . ([1957]1997), The Poverty of Historicism, London: Routledge \& Kegan Paul. . ([1962]1971), The Open Society and Its Enemies, Princeton: Princeton University Press. (Preface to first edition dated 1943).

. (1974), Objective Knowledge - an evolutionary approach, Oxford: Clarendon Press. . (1985), Popper Selections, ed. D. Miller, Princeton, NJ: Princeton University Press. . ([1988]1992), In Search of a better world: lectures and essays from thirty years; transl. Laura J. Bennett, London and New York: Routledge.

SHEARMUR, J., (1996), The Political Thought of Karl Popper, London and New York: Routledge. STOKES, G., (1998), Popper: Philosophy, Politics and Scientific Method, Cambridge: Polity. VERNON, R., (1976), “The 'Great Society' and the 'Open Society': Liberalism in Hayek and Popper”, Canadian Journal of Political Sciences, 9, 2 (1976). 